Available online at www.refaad.com

VMPH, 1(1)2020, 1-2

Case Report

Veterinary Medicine and Public Health Journal (VMPH)

Journal Homepage: https://www.refaad.com/views/vmph/home.aspx

\title{
An unusual case of type iv monteggia fracture and concurrent humoral fracture in an arabian foal
}

\author{
Mousa Daradka ${ }^{a *}$, Musa Alshehabat ${ }^{b}$, Ahmad Almomany ${ }^{c}$ \\ a,b,c Department of Veterinary Clinical Sciences, Faculty of Veterinary Medicine, Jordan University of Science and \\ Technology, Jordan \\ *Corresponding author: Mousa Daradka (daradka@just.edu.jo)
}

How to cite this article: Daradka et al. An Unusual Case of Type IV Monteggia Fracture and Concurrent Humoral Fracture in an Arabian Foal, Veterinary Medicine and Public Health Journal, 1(1);(2020): 1-2.

DOI: https://doi.org/10.31559/vmph2020.1.1.1

Received Date: 19/10/2019 Accepted Date: 12/11/2019

\begin{abstract}
A 7-month-old, 250-kg male Arabian foal with a history of an acute, non-weight bearing lameness of the right forelimb after a barn accident is being reported here. The combination of a humero-radial luxation and complete dislocation of the ulna and a mid-diaphyseal fracture of the humerus is being reported for the first time in an Arabian foal in this case report.
\end{abstract}

Keywords: Arabian foal; Monteggia fracture; elbow luxation.

\section{Introduction}

Monteggia fracture is rarely encountered in both human and veterinary practices. Only few case reports could be cited in recent literature describing this rare traumatic injury in humans and animals (Schartz and Schrader 1984; Ring and Waters 1996; Ring et al. 1998; Prassinos 2006; Jalim et al. 2009; Bush and Owen 2009). In human medicine, this type of fracture accounts for less than 5\% of all forearm fractures (Ring and Waters 1996). Monteggia fracture refers to a fracture of the proximal third of the ulna with dislocation of the head of the radius (Vallone and Schulz 2011). This classification of fractures was first described by Monteggia (Beutel 2012). Later, the classification of this type of fractures was expanded by Bado (1967) to include 3 categories based on the direction of the radial head luxation (Bado 1967; Beutel 2012). More recently, type IV Monteggia fracture was described as cranial displacement of the radial head combined with ulnar and radial fracture (Schartz and Schrader 1984).

\section{Case report}

A 7-month-old, approximately 250-kg male Arabian foal was presented to the Veterinary Health Canter at Jordan University of Science and Technology with an acute, non- weight- bearing lameness of the right forelimb after a barn accident. The owner had indicated that the foal was tied to a solid stationary wall near the horse rail at the time of the incident when the foal suddenly panicked from a nearby noise where he tried to get loose but could not break the twine. The foal repeatedly tried to pull back, lifting his thoracic limbs up and down until he intertwined himself. The twine was trapped into the medial side of the right shoulder leaving the foal nonweight bearing.

On admission, the foal was non-weight bearing on the right forelimb (lameness grade 5 on a scale of 1 to 5). The right elbow was apparently swollen with a dropped elbow appearance. Manipulation of right elbow revealed pain and discomfort. Haematological and serum biochemical analyses were performed and the results were within normal limits. Medio-lateral radiographic view of the right elbow was obtained. There was a complete luxation of the humero-radial joint, completely displaced ulna and an oblique middiaphyseal humeral fracture (Fig 1). Ultrasonography (10 $\mathrm{MHz}$ linear probe) of the affected area revealed complete disruption of the lateral collateral ligaments of the elbow. Based on the above findings, a diagnosis of type-IV Monteggia fracture and concurrent humeral fracture was accomplished. In this case, no treatment was attempted because of the projected poor prognosis and limited financial resources on the owner's side. 
The foal was humanely euthanatized using an anaesthetic overdose (Beuthanasia-D, Intervet Inc.,

\section{Discussion}

In here, we are reporting an unusual presentation of Monteggia fracture in a foal in which the radial head was cranially luxated, the ulna was completely separated and displaced, and the humerus was fractured. Fractures involving the elbow joint are not easy to repair in horses (Jalim et al. 2009). In cases of incomplete or nondisplaced fractures, conservative therapy might be rewarding (Dearo et al. 2010). The use of splints or Robert Jones bandages is still controversial as it may results in undue damage to local soft tissues of the area due to a pendulum effect (Dearo et al. 2010). Nonetheless, many olecranon fractures displace under the influence of the triceps muscle and require stronger, more stable form of internal fixation for optimum results (Auer 2006). In here, the ulna was completely displaced and repair could have presented a major task to replace displaced olecranon. In one report, surgical repair of type IV Monteggia fracture in a foal was attempted using a dynamic compression plate (Jalim et al. 2009). The most common complications were atrophy of triceps brachii, mild carpal flexor contracture, and metacarpophalnegal joint fracture 2 months after surgery.

In this case report, a combination of humeroradial luxation and complete dislocation of the ulna and mid-diaphyseal fracture of the humerus is described for the first time in an Arabian foal.

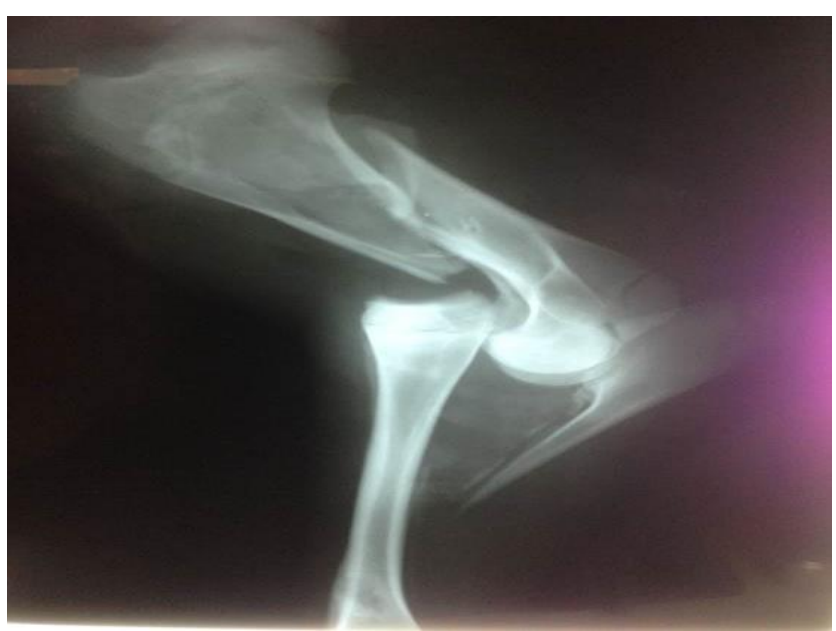

Fig (1): Medio-lateral radiographic view of the right elbow of a 7-month-old Arabian foal showing type-IV Monteggia fracture characterized by a complete luxation of the humero-radial joint, completely displaced ulna and oblique mid-diaphyseal humeral fracture.

\section{Note}

Refaad and VMPHJ remain neutral with regard to jurisdictional claims in published institutional affiliation.

\section{References}

[1] Auer. JA., Equine Surgery, 3rd edition, Philadelphia, Pennsylvania. WB Saunders, (2006),1001-1029.
Madison,

NJ,

USA).

[2] Bado. JL., The Monteggia Iesion, Clin Orthop Relat Res, 50(1967), 71-86.

[3] Beutel. BG., Monteggia fractures in pediatric and adult populations, Orthopedics, 35(2)(2012),13844, https://doi.org/10.3928/01477447-20120123-32

[4] Bush. M. \& Owen. M., Type-IV variant Monteggia fracture with concurrent proximal radial physeal fracture in a Domestic Shorthaired Cat, Vet Comp Orthop Traumatol, 22(3)(2009),225-8, https://doi.org/10.3415/vcot-08-06-0048

[5] Dearo. ACO., Fonteque. JH. \& Vidal. FD., Surgical repair of an olecranon fracture in a horse, Ciências Agrárias, 31(1)(2010),197-204, https://doi.org/10.5433/1679-0359.2010v31n1p197

[6] Jalim. SL., Mckinnon. AO. \& Russell. TM., Case report: Repair of a type IV Monteggia fracture in a foal, Aust Vet J , 87(11)(2009),463-466, https://doi.org/10.1111/j.1751-0813.2009.00508.x

[7] Prassinos. NN., Fractures combination of the proximal antebrachium in an immature dog that resembles Monteggia fracture, Vet Comp Orthop Traumatol, 19(3)(2006),184-6, https://doi.org/10.1055/s-0038-1632996

[8] Ring. D., Waters. PM., Operative fixation of Monreggia fractures in Children, Jf Bone Joint Surg, 7(8)(1996), 734-9.

[9] Ring. D., Jupiter. JB. \& Waters. PM., Monteggia fractures in children and adults, J Am Acad Orthop Surg, 6(4)(1998),215-24, https://doi.org/10.5435/00124635-199807000-00003

[10] Schartz. PD. \& Schrader. SC., Ulnar fracture and dislocation of the proximal radial epiphysis (Monteggia lesion) in the dog and cat: a review of 28 cases, J Am Vet Med Assoc, 185(1984),190-4.

[11] Vallone. L. \& Schulz. K., Repair of Monteggia Fractures Using an Arthrex Tightrope System and Ulnar Plating. Vet Surg, 40(6)(2011),734-737, https://doi.org/10.1111/j.1532-950x.2011.00848.x

$* * * * * * * * * *$ 